\title{
Horizontal and vertical distribution of wind speed in a vegetation canopy
}

\author{
A. F. G. JACOBS ${ }^{1} \&$ J. H. VAN BOXEL 2 \\ 1 Department of Meteorology, Wageningen Agricultural University, P.O. Box 9101, NL \\ $6700 \mathrm{HB}$ Wageningen, Netherlands \\ 2 Department of Physical Geography and Soil Science, University of Amsterdam, Nieuwe \\ Prinsengracht 130, NL 1018 VZ Amsterdam, Netherlands
}

Received 4 April 1991; accepted 16 May 1991

\begin{abstract}
Wind speed measurements within a maize row canopy were carried out to investigate the horizontal and vertical variability of the mean wind speed and its standard deviation. Attention was given in finding adequate scaling parameters of the within-canopy wind speed profiles under various atmospheric stratification states. Moreover, a validation of existing model simulations was carried out. It appears that in the horizontal the mean wind speed and its standard deviation can vary about $20 \%$ from its spatial mean value. During day-time and night-time the friction velocity appears to be a good scaling parameter. Clear nights, however, are exceptions when the above-crop wind speed drops to a very low value. Then the free convection velocity scale appears to be an appropriate scaling parameter for the within-canopy processes. The canopy models of Wilson \& Shaw (1977) and Li et al. (1985) do simulate the spatially averaged mean wind profile within the range of the horizontal variability.
\end{abstract}

Keywords: wind speed, wind speed deviation, wind speed variability, crop canopy

\section{Introduction}

Air movement just above and within a row crop canopy is characterized by complex interactions of the air mass above the canopy and the air mass within the canopy. The air movement far above a horizontally homogeneous canopy behaves twodimensionally. In the vicinity of the top of the canopy, in the so-called roughness layer, the state of the flow becomes more complex, instantaneously as well as averaged in time. Serious deviations from the spatial averaged mean value can occur due to direct sensing of incidental roughness elements by the flow. Here, the mean flow becomes essentially three-dimensional and spatially variable. As a rule of thumb (see Figure 1), we may expect that the vegetation layer lies between $0<z<\left(d+z_{o}\right)$ and the roughness layer between $d<z<\left(d+20 z_{o}\right)$, where $h$ is the canopy height, $d$ is the displacement height and $z_{0}$ is the roughness length (Tennekes, 1982). Within the canopy, between the roughness elements, this three-dimensional 


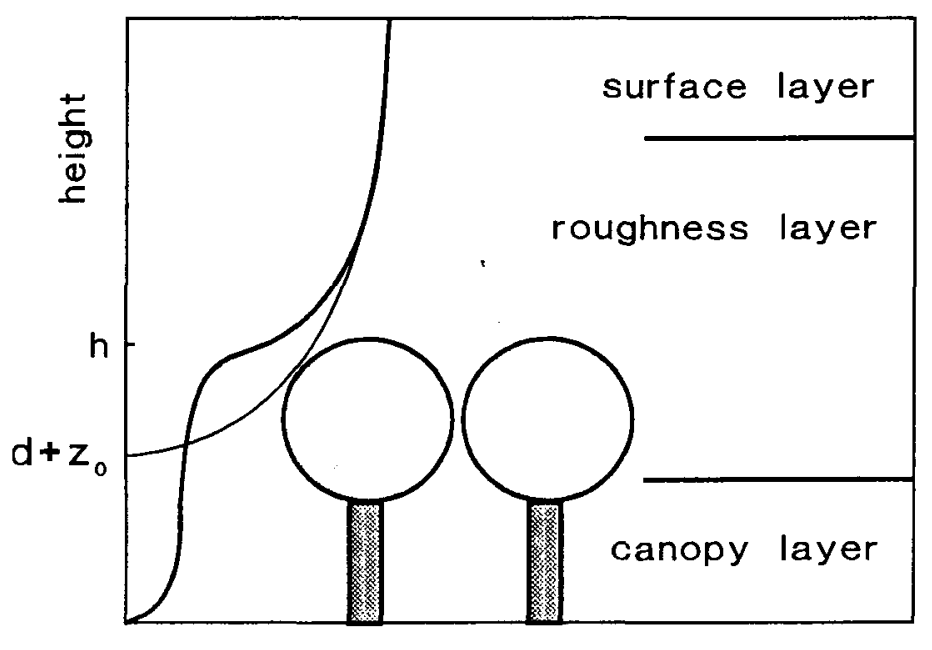

wind speed

Fig. 1. An outline of the most significant flow regions near the earth's surface. Bold line: shape of the actual mean wind profile. Thin line: extrapolated mean wind profile according to the log-profile.

behaviour will be even enhanced, since here the flow is completely disturbed by canopy elements.

In practice, when for example mean flow values are desired for the just above or within crop canopy flow, this means that one-point measurements at one level are not sufficient any more to describe the wind field properly. At more than one point at a particular level measurements must be taken, and roughly speaking it may be expected that the number of measurements needed will strongly depend on the irregularity of the architecture of the vegetation, and, of the desired accuracy.

Only in a few outdoor experiments close to the surface, have elements been executed in which aspects of the vertical and horizontal variability of the flow have been measured. For example, Shaw et al. (1974), and Mulhearn \& Finnigan (1978) made some observations of turbulence and turbulent transports of momentum and heat above a rough surface rather close to the roughness elements. Graser et al. (1987) studied temperature patterns within sorghum canopies with different row spacing. Concerning the wind speed, however, no systematic outdoor observation are know by the authors.

An important reason for a lack in experimental wind speed profile evidence, which is well spatially averaged, is that the velocity is a vector quantity, which is much more difficult to measure accurately than a scalar quantity. In particular this is difficult within the roughness layer and canopy layer since here the mean flow characteristics are essentially three-dimensional. Also instrumental restrictions are responsible for this shortcoming. For example, just above and within a plant community, the measuring volume of an anemometer must be small in order not to disturb the flow, but here also, the leaves are fluttering and may not be allowed to obstruct the functioning of the sensor. Besides that, the wind speed within a canopy 
is often very low $\left(<<1 \mathrm{~m} \mathrm{~s}^{-1}\right)$ and has a high turbulence intensity, $\left(\sigma_{\mathrm{U}} / \mathrm{U}\right)$, (ranging between 2 and 5) which requires expensive fast-response anemometers in the low wind speed range.

It is our purpose here to delineate some of the characteristics of canopy flows and in particular the objective of the present study is:

(1) to obtain insight into the spatial mean averaged wind profile and its standard deviations,

(2) to examine the governing scaling parameters of the within-canopy wind speed profile and standard deviation,

(3) to validate some existing flow models that simulate the mean flow profiles just above and within a canopy.

\section{Theory}

Under a steady state and thermally neutral stratification, the wind profile near the earth's surface in the surface layer $\left(z>d+20 z_{0}\right)$ can be adequately described by the logarithmic profile:

$$
\left.u(z)=u^{*} / x\right) \text { In }\left((z-d) / z_{\mathrm{o}}\right)
$$

where $u(z)$ is the mean wind speed at height $z, u^{*}$ is the friction velocity and $\varkappa=$ 0.4 is Von Karman's constant.

For the simpler canopies (i.e. canopies with constant foliage area distribution and a homogeneous turbulent intensity) it can be shown (Cionco, 1965; Goudriaan, 1977) that that within the canopy the mean flow follows the expression:

$$
u(z)=u(h) \exp (-\alpha(1-z / h))
$$

where $h$ is canopy height and $u(h)$ is mean wind speed at this height. This expression prescribes an exponential decrease with the depth into the canopy, the rate of decrease being dependent on the index, $a$ which is dependent on canopy parameters. The index $a$ can range between 0.5 and 3, and, because it refers to the degree of decoupling between the above-canopy and within-canopy flow, is often called the decoupling factor (Cionco, 1978). For many simple crop canopies, mean values for the decoupling factor have been persued and can be found in for example Cionco (1972).

During the past two decades, various models with different degree of complexity have been proposed to describe the mean wind profile and turbulent processes within and just above a plant canopy. Wilson \& Shaw (1977) proposed a second-order closure scheme for neutral stratification and Meyers \& Paw U (1986) for diabatic situations. These second-order models produce realistic results, however, for easy use in practice they proved to be complicated. That is why there is a tendency for models which contain sophisticated fluid mechanics but which are easier to understand and to manipulate in comparison with the second-order closure schemes. An example is the model of $\mathrm{Li}$ et al. (1985), who introduced the alternating processes 
of downsweeps and ejections, by adding a non-local term to the first-order closure scheme.

In the present study, the collected experimental evidence will be compared with the model results of Wilson \& Shaw (1977) and with a variant (van Pul \& van Boxel, 1989) of the model of $\mathrm{Li}$ et al. (1985).

\section{Materials and methods}

In addition to a continuous measurement program in which the fluxes of heat, mass and momentum were estimated above and within a maize crop canopy (Jacobs \& van Boxel, 1988), a more detailed turbulence experiment was carried out at the pilotfarm Sinderhoeve $\left(51^{\circ} 59^{\prime} \mathrm{N}, 5^{\circ} 45^{\prime} \mathrm{E}\right)$ during two weeks in July, 1986. Instruments, important for this study only will be discussed here briefly.

Above the crop, the mean wind profile was measured with cup anemometers at eleven levels at heights above the ground of $1.7,2.2,2.85,3.5,4.25,5.0,6.0,7.0$, $8.0,9.0$, and $10 \mathrm{~m}$. The cup-type anemometers were home-made; the starting speed is $0.20 \mathrm{~m} \mathrm{~s}^{-1}$ and the first-order response distance $(66 \%)$ is $0.90 \mathrm{~m}$. The abovecanopy wind profile data provide data about the two surface characteristics: $d$ and $z_{0}$, and their course during the growing season (Jacobs \& van Boxel; 1989a,b). The mean temperature and moisture profiles were measured at two levels at heights of 2.0 and $4.0 \mathrm{~m}$ with home-made aspirated psychrometers. At a height of $4.5 \mathrm{~m}$, a 3-D sonic anemometer of Kaijo Denki (DAT-310) with an additional fast-response thermometer (van Asselt et al., 1991) and Lyman- $\alpha$ sensor were installed. These instruments provide data about the above-crop thermal stratifcation of the atmosphere.

Within the canopy, in the middle of two rows, the mean wind speed profile was estimated with hot-sphere anemometers (Stigter et al., 1977) at heights above the ground of $0.1,0.2,0.3,0.4,0.7,1.0$ and $1.4 \mathrm{~m}$. To gain insight into the horizontal variability of the wind speed, measurements were made at two levels, 0.3 and 0.7 $\mathrm{m}$, at $0.25 D, 0.50 \mathrm{D}, 0.75 \mathrm{D}$ and $0.05 \mathrm{D}$, where $D$ is the row distance. Moreover, a 1-D sonic anemometer of Kaijo Denki (PAT-110) with an additional fast-response thermometer and a Lyman- $\alpha$ sensor were installed at a height of $0.7 \mathrm{~m}$ to provide data about the within-canopy transports of heat and water vapour.

The hot-sphere anemometers are very suitable for measuring low wind speeds (measuring range $0.02-2.0 \mathrm{~m} \mathrm{~s}^{-1}$ ). Since these anemometers have no moving parts they cannot be blocked by flapping leaves or other canopy structures. The hotsphere anemometers were calibrated in a low-wind speed tunnel, where it appeared that their accuracy was better than $5 \%$. A restriction of the hot-sphere anemometers is that the absolute wind speed is measured and no information is obtained about the wind direction. Their measuring volume is small (sphere diameter ca 3 $\mathrm{mm}$ ) and their first-order response time is wind speed dependent and is about $10 \mathrm{~s}$ at $1 \mathrm{~m} \mathrm{~s}^{-1}$, which is relatively long. The latter feature means that the wind speed fluctuations and the consequent standard deviation are underestimated.

The maize crop (Zea mays L., cv. Vivia) was planted in rows $0.75 \mathrm{~m}$ apart, with plants $0.11 \mathrm{~m}$ apart in the row. The rows were orientated NNE-SSW. During the 


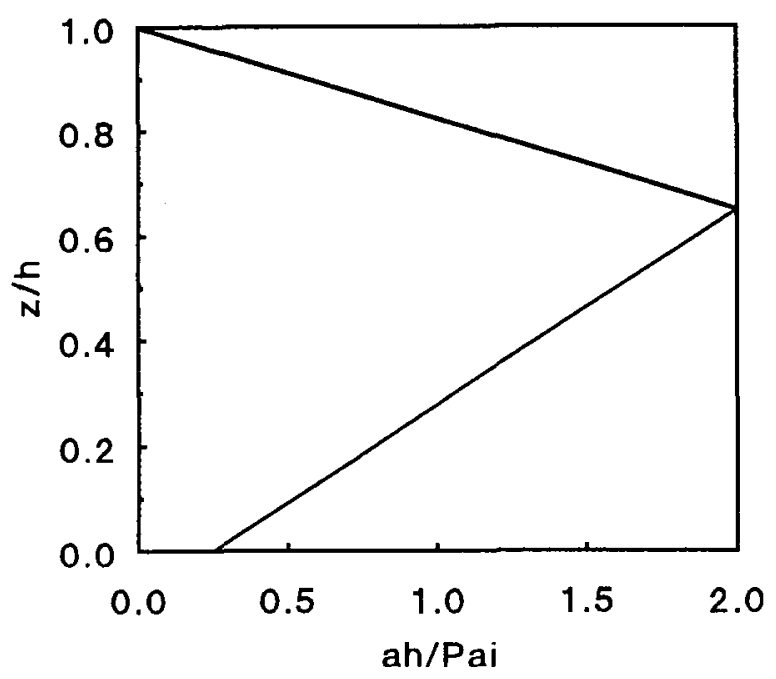

Fig. 2. The nondimensionized plant area distribution, a, vs the nondimensionized height. The area under the curve is equal to 1 .

detailed turbulence experiment the crop growth occurred at the end of the vegetative state, had a height, $h$, of $1.70 \mathrm{~m}$ and the one-sided plant area index, PAI, was 3.6. The plant area distribution, $a$, which is an important parameter in modeling the within-canopy flow, has been plotted in Figure 2 in nondimensionized form. The plant area distribution is defined as the one-sided plant (i.e. leaves and stems) area per unit volume.

The fast-response instruments were all sampled with $10 \mathrm{~Hz}$, while the slowresponse instruments were sampled with $1 \mathrm{~Hz}$. All the data was carried to a mobile measurement van, about $100 \mathrm{~m}$ from the instruments. Here, the unconditioned data was dumped on a digital magnetic tape for further analysis. More details about measurement techniques are provided in Jacobs \& van Boxel (1988a).

\section{Results and discussion}

To get insight into characteristics on the course of the wind speed profile during a particular day (29 July, 1988), in Figure 3 the 30-minutes mean profiles, measured in the centre of the row, have been depicted. Here, the heights have been nondimensionized with the height of the canopy $(h=1.7 \mathrm{~m})$. From this result it can be inferred that, as must be expected, the maximal wind speed occurs at the top of the canopy. Moreover, especially during day-time, a second local maximum occurs in the lower region $(z / h \sim 0.1)$ of the canopy. This secondary maximum is also present during night-time, but, less pronounced. This particular day was characterized by a relatively strong wind $\left(u(10 \mathrm{~m})>5 \mathrm{~m} \mathrm{~s}^{-1}\right)$, and an overcast sky, hence the thermal stratification was mostly near-neutral $(|L|>30 \mathrm{~m}$, where $L$ is the Obukhov thermal length scale). 


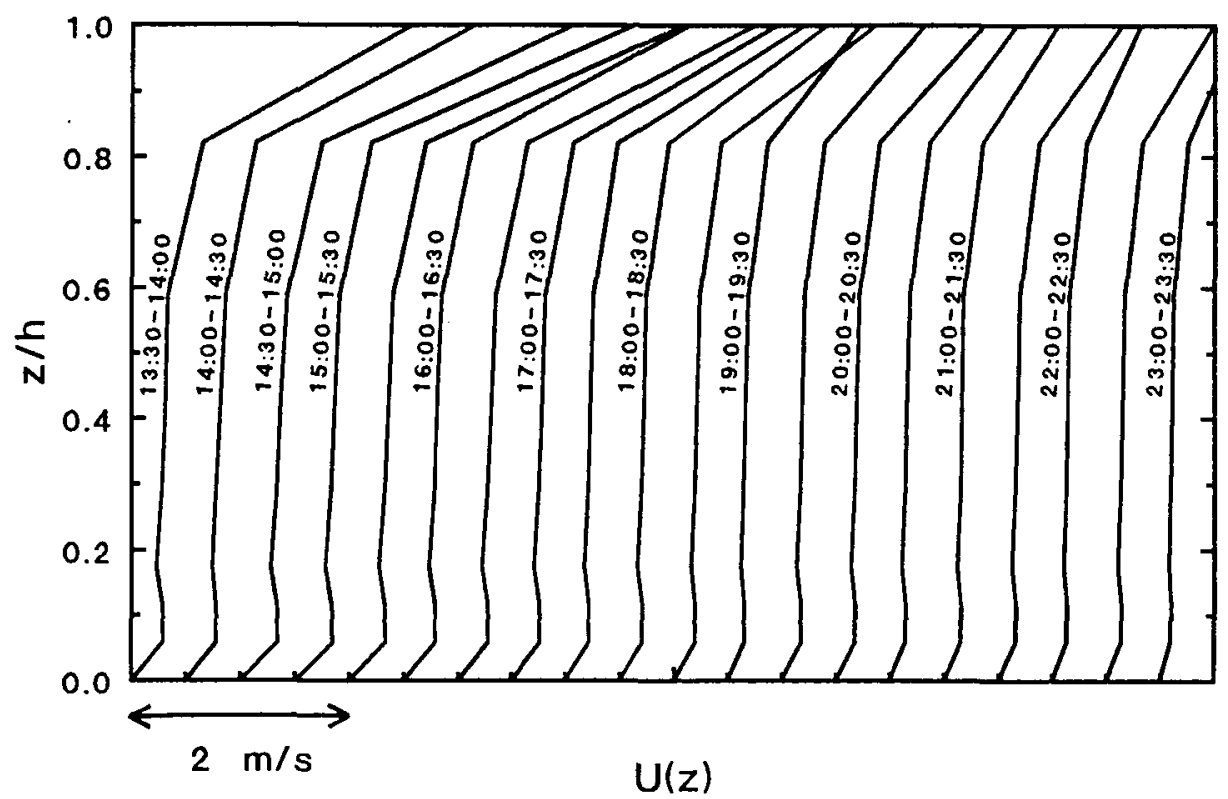

Fig. 3. The course of the within-canopy absolute wind profile during a windy and cloudy day (29 June 1988).

At the top of Figure 4, the same wind profiles as given in Figure 3 have been plotted. Here, the wind speeds are nondimensionized with the friction velocity, $u^{*}$, and were selected for near-neutral stratification $(|L|>30 \mathrm{~m})$. It can be inferred from this result that the dimensionless profiles are similar in shape under near-neutral stratification and scale excellently with the above-canopy friction velocity, $u^{*}$. About the same result with different scaling can be obtained if the profiles are nondimensionized with a mean reference wind speed being taken above the roughness layer. We choose the friction velocity since this velocity is a more appropriate scale for most turbulent exchange processes (Tennekes, 1982) near the earth's surface.

At the bottom of Figure 4 the results for July 1986 have been plotted for a much wider thermal stratifcation range $(L>5 \mathrm{~m}$ and $L<0 \mathrm{~m})$. From this result we can conclude that the thermal stratification does somewhat affect the within-canopy wind profile but also that the above-canopy friction velocity, $u^{*}$, remains a suitable scaling parameter.

At the top of Figure 5, the central row standard deviations of the wind speed, $\alpha_{u}$ $=\operatorname{sd}(u)$, nondimensionized with the friction velocity, $u^{*}$, have been plotted for 29 June. These results also show similar shapes, and scale also excellently with the above-canopy friction velocity, $u^{*}$. It must be noted, however, that due to the relatively long time constant of the anemometers a part of the high-frequency range ( $n$ $>0.1 \mathrm{~Hz}$ ) has been cut-off. Consequently, the present results are an underestimation of the real standard deviations. Nevertheless, in main lines this result agrees within a few percentages with those found by others (see e.g. Wilson et al., 1982). 

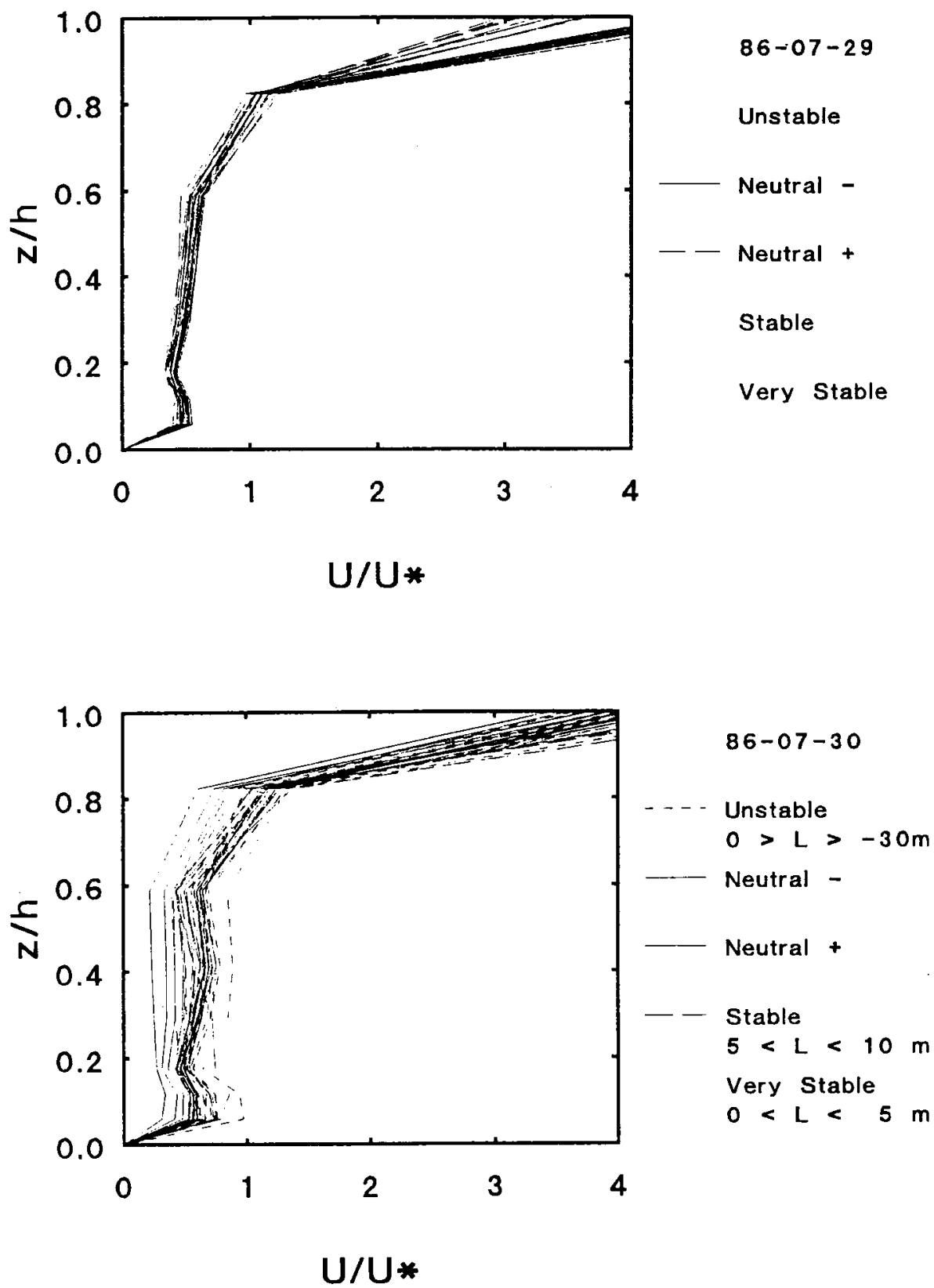

Fig. 4. The 30-minutes averaged within-canopy absolute wind profiles measured in the middle between two rows. The top shows results of 29 July 1986 under near-neutral conditions only $(|L|>30 \mathrm{~m})$, while the bottom shows results of 30 July 1986 under a wider stratifcation range $(L>5 \mathrm{~m}$ and $L<0 \mathrm{~m})$. 
A. F. G. JACOBS AND J. H. VAN BOXEL
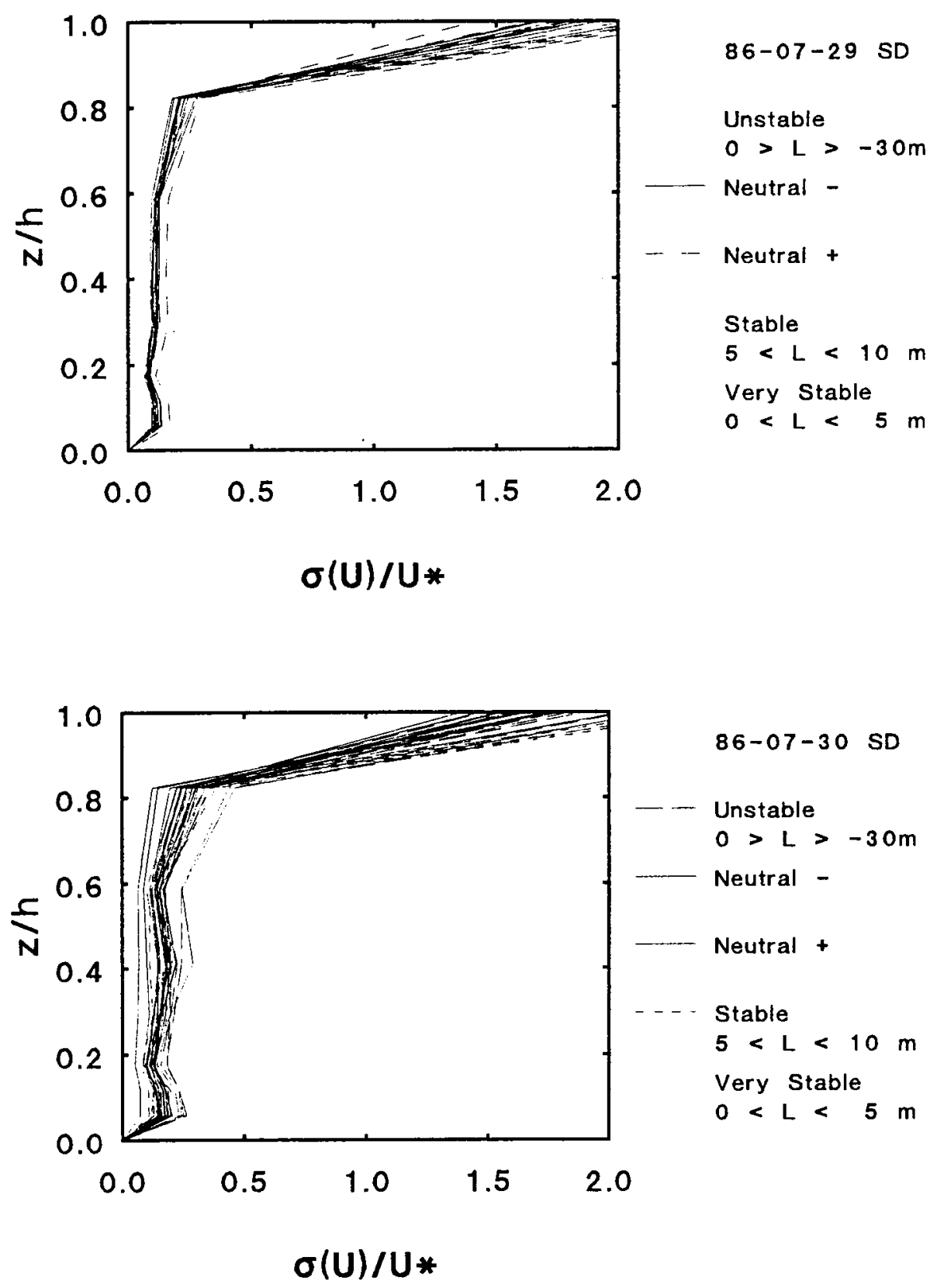

Fig. 5. The 30-minutes averaged within-canopy standard deviation profiles measured in the middle between two rows. The top shows results of 29 July 1986 under near-neutral conditions only $(|L|>30 \mathrm{~m})$, while the bottom shows results of 30 July 1986 under a wider stratification range $(L>5 \mathrm{~m}$ and $L<0 \mathrm{~m})$. 


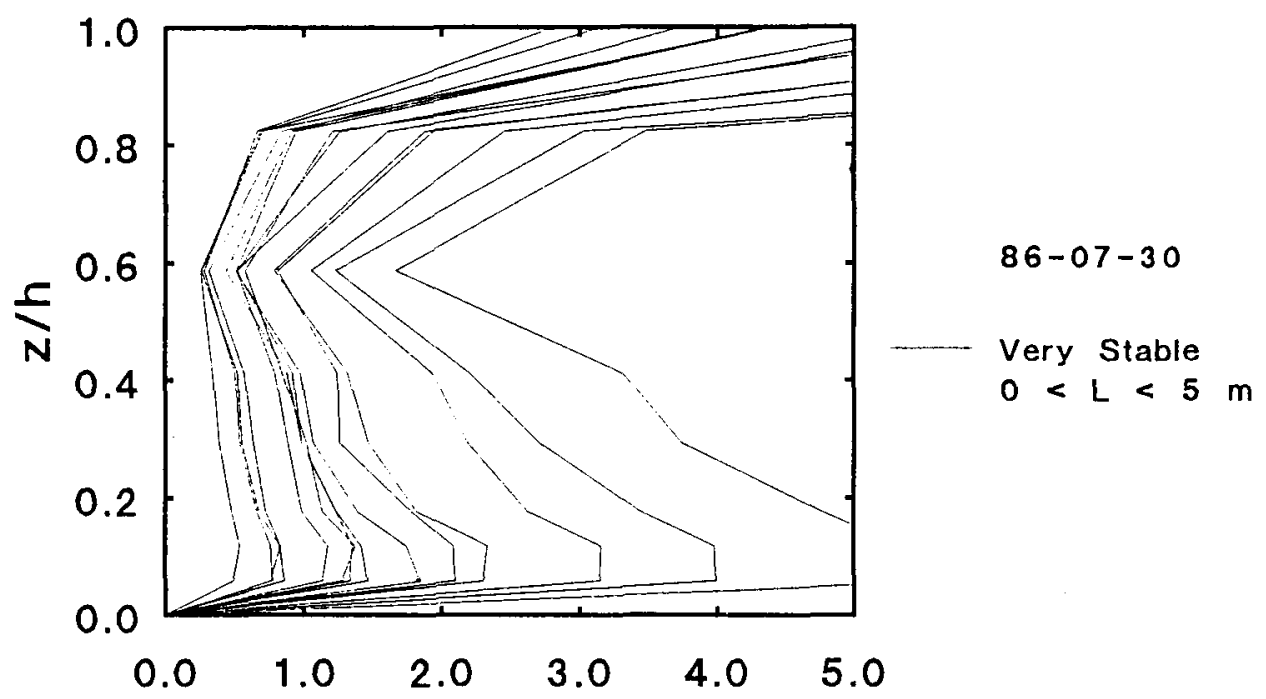

\section{U/U*}

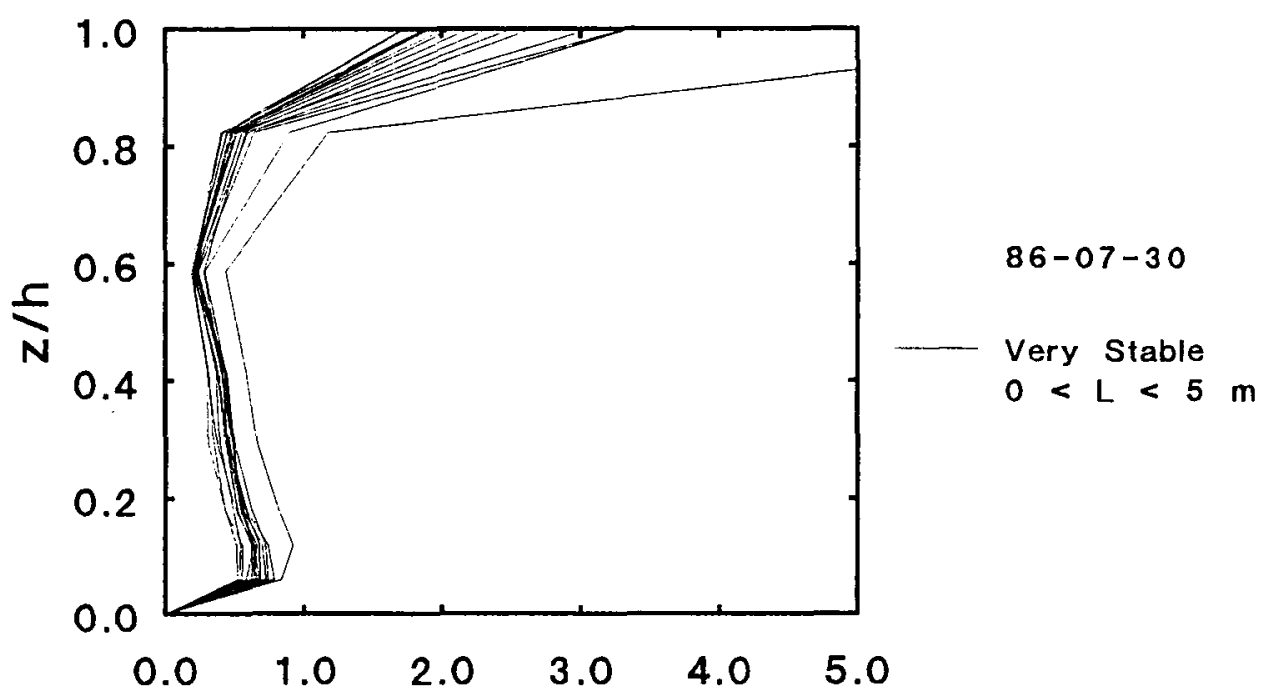

\section{$\mathrm{U} / \mathrm{W} *$}

Fig. 6. The within-canopy wind speed profiles under extreme stable conditions $(0 \mathrm{~m}>L>5 \mathrm{~m})$, measured on 30 July 1986. The top represents the data nondimensionized with the friction velocity, $u^{*}$, and the bottom with the free convection velocity scale, $w^{*}$. 
A. F. G. JACOBS AND J. H. VAN BOXEL

$0.30 \mathrm{~m} 1$ row

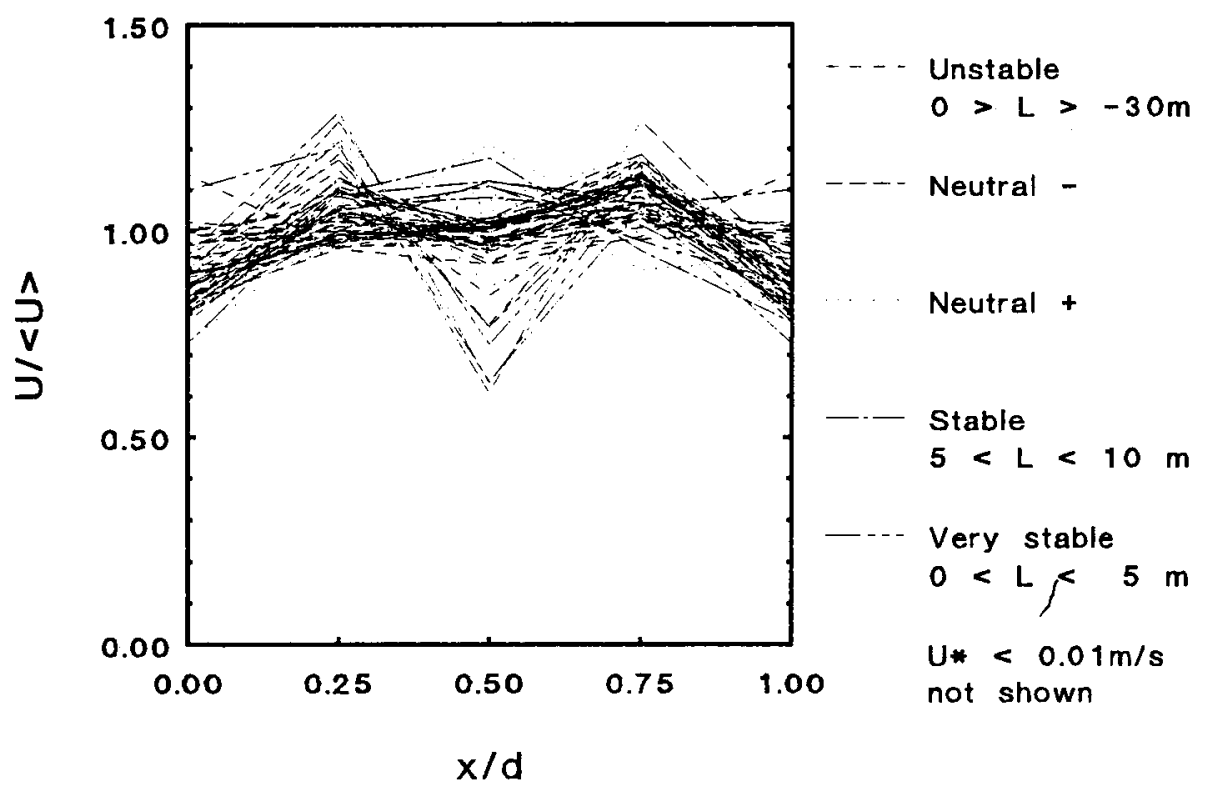

$0.30 \mathrm{~m} 1$ row

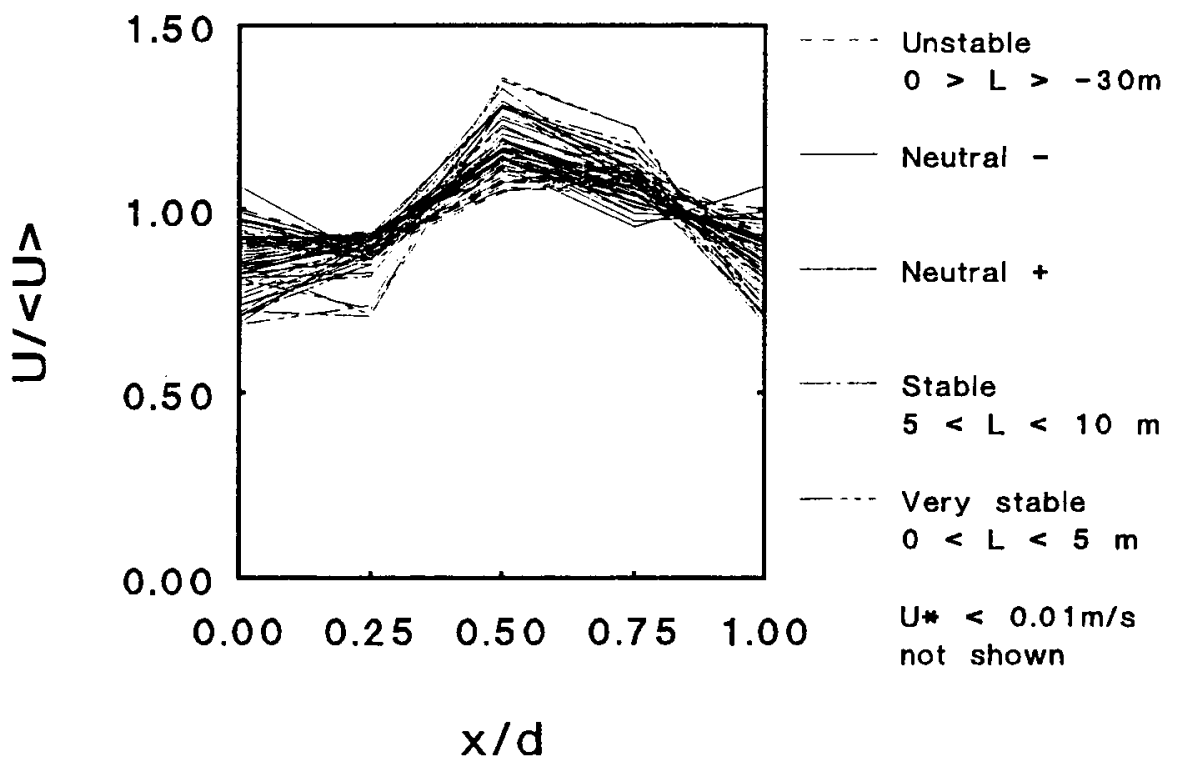

Fig. 7. The relative within-canopy wind speed with regard to the spatial averaged values at two levels. Top: $z / h=0.4$, bottom: $z / h=0.2$ ). 
At the bottom of Figure 5 the within-canopy standard deviations for 30 July 1986 selected for have been plotted under a wider thermal stratifcation range $(L>5 \mathrm{~m}$ and $L<0 \mathrm{~m}$ ). From this result it can be concluded that the standard deviation is more affected by the thermal effects than the mean wind profile; but the results still scale with the above-canopy friction velocity, $u^{*}$.

At the top of Figure 6, mean wind speed profiles, measured on July 30, have been depicted, selected for above-crop very stable conditions $(0 \mathrm{~m}<L<5 \mathrm{~m})$. These situations occur during calm nights, when the top of the canopy cools by radiation losses while the floor of the canopy is forced by the soil heat flux. Under these conditions, the within-canopy air is statically unstable and decoupled from the above-canopy region. Within the canopy a free convection state occurs in which free convection cells are generated by the relatively warm canopy floor. The thermal eddies are fed for energy at the soil floor while the height of the crop is a measure for the stable layer capping the unstable vegetation layer. The boyancy flux at the floor and the crop height, $\mathrm{H}$, are the two variables to be important in this free convection state. Combining these scales yield a free convection velocity scale, $w^{*}$, defined according to (Tennekes \& Lumley, 1972):

$$
w^{*}=\left[(g h / T)\left(\overline{\left(\mathrm{w}^{\prime} \mathrm{T}^{\prime}\right.}\right)\right]^{1 / 3}
$$

where, $g$ is gravity, and $\overline{\mathrm{w}^{\prime} T^{\prime}}$ the turbulent kinematic heat flux at the soil floor. A good estimate at night-time for the kinematic heat flux at the floor is $\overline{\mathrm{w}^{\prime} T^{\prime}}$ $q_{\mathrm{s}} /\left(\varrho c_{\mathrm{p}}\right)$, where $q_{\mathrm{s}}$ is the soil heat flux at the ground and $\left(\varrho c_{\mathrm{p}}\right)$ the volumetric heat capacity of air, since during night-time most of the soil heat flux is transformed into sensible heat (Garrat \& Segal, 1988). In a within-canopy free convective situation, $w^{*}$ is to be expected a more convenient turbulence velocity scale than the decoupled above-canopy friction velocity scale, $u^{*}$.

At the bottom of Figure 6, the same results have been depicted nondimensionized with the free convection scale, $w^{*}$. From this result it clearly can be inferred that under above-canopy very stable stratification, the within-canopy free scaling velocity, $w^{*}$, is indeed a much better scaling parameter than the above-canopy friction velocity scale, $u^{*}$.

The result depicted in Figure 6 also reveals that the absolute wind speed profiles under above-crop very stable conditions show a clear minimum at a height of $z / h$ $=0.6$. This suggests that the free convection height is more or less restricted to this level; below $z / h=0.6$ the free convection states dominates, above this height the wind speed forcing from above the canopy dominates. It is interesting to note that the height $z / h=0.6$ coincides (see Figure 2) with the maximum of the plant area distribution.

In Figure 7, the relative horizontal wind speed distribution with regard to the spatial averaged wind speed, $\langle u\rangle$, have been plotted for two levels $(z / h=0.4,0.2)$. This result indicates that within a row crop the mean wind speed can vary about $20 \%$ from its spatial mean value. Moreover, this result suggests that in the lower region $(z / h=0.2)$ the spatial maximal value occurs more or less in the centre of the row. The latter must be expected since in the lower region (see Figure 2) the 
canopy is most sparse, and, in addition, here the plant elements are most concentrated near the stems. The higher region result $(z / h=0.4)$ reveals that here the horizontal wind speed distribution is more evenly distributed. This also must be expected since in the top region of the maize canopy the largest contribution to the plant area index, PAI, occurs, and, in addition, here the plant elements are spatially most evenly distributed.

In Figure 8 the model results of the within-canopy wind speed profiles as well as experimental data have been plotted. The top represents the near-neutral states which must agree best with the model results. From Figure 8 it can be inferred that both models clearly simulate the secondary maximum in the lower canopy region,
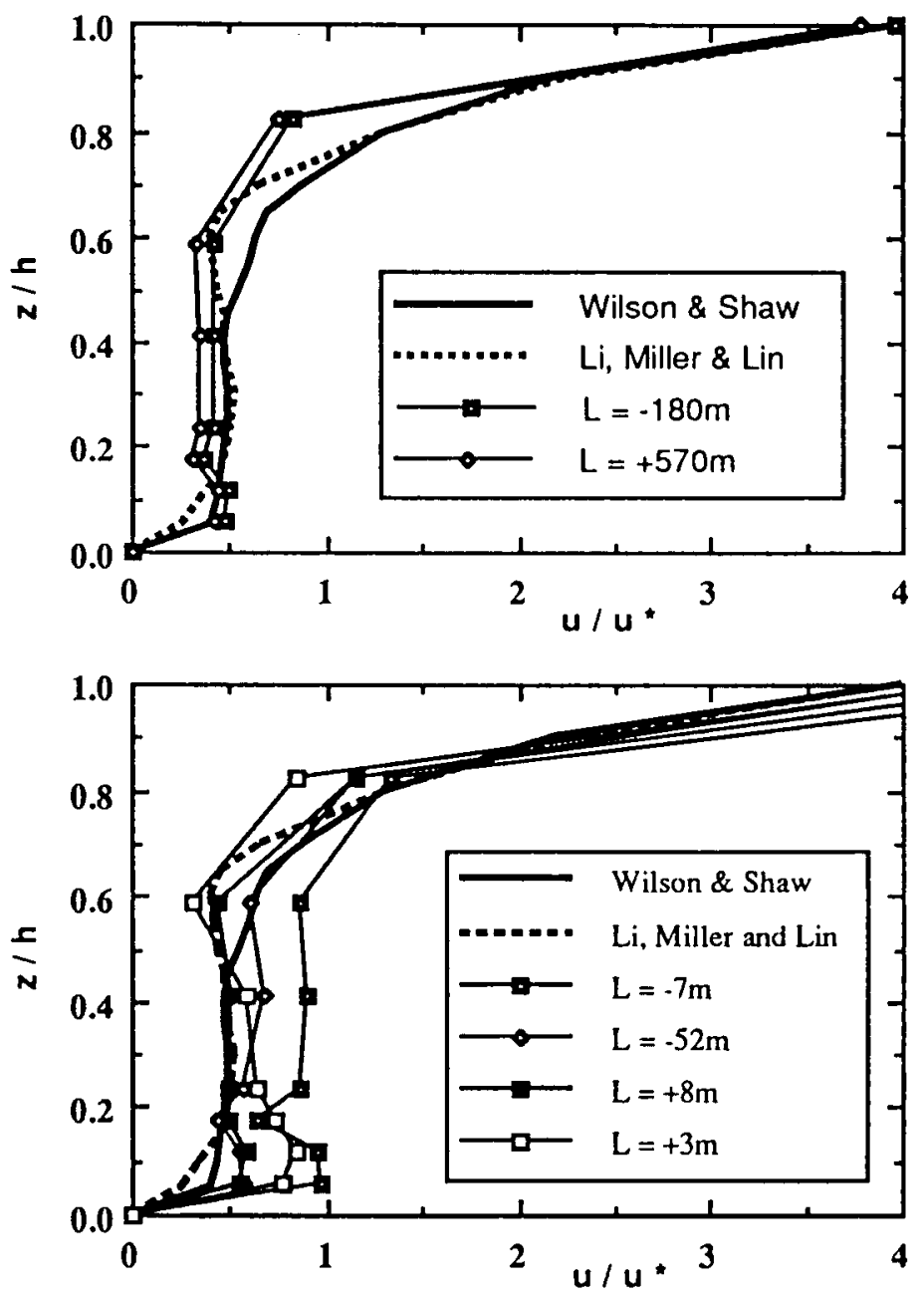

Fig. 8. Model simulations compared with experimental results under various stratification states. 
and, in addition, agree with the experimental evidence within the horizontal wind speed variation of about $20 \%$. The bottom results of Figure 8 compares the model results with the experiments under above-canopy diabatic states. From this result it appears that for above-canopy stable cases $(L>5 \mathrm{~m})$ the model results agree also well (within the horizontal variability) except for the very stable states $(0 \mathrm{~m}<L<$ $5 \mathrm{~m}$ ). The latter must be expected since both models only describe atmospheric neutral states. From the above-canopy unstable states depicted in Figure 8 we can infer that, roughly speaking, the shape of the wind speed profiles is conserved within the canopy, however, that serious deviations from the neutral states already occur in not too unstable conditions $(L<-60 \mathrm{~m})$.

\section{Conclusions}

From the foregoing results the following main conclusions can be drawn:

(1) The horizontal variability of the mean wind speed in a row crop is restricted to about $20 \%$ of its spatial mean value. Here in the lower region $(z / h<0.6)$, the maximal value occurs in the centre between the rows while the minimal value occurs near the stems. In the higher region $(z / h>0.6)$ the horizontal distribution is more evenly distributed.

(2) In most stratification states $(L>5 \mathrm{~m}$ and $L<0 \mathrm{~m}$ ) the within-canopy mean wind profiles as well as their standard deviations, can excellently be scaled by the above-canopy friction velocity, $u^{*}$, or by a mean above-canopy reference wind speed. This means that above-canopy and within-canopy flow is strongly coupled.

(3) Under above-canopy very stable stratification ( $0 \mathrm{~m}<L<5 \mathrm{~m}$ ) a decoupling between the above-canopy and within-canopy flow occurs. Here, the within-canopy free convective flow is mainly forced by the soil heat flux at the floor of the canopy. The height of the convective cells are restricted by the top layer of the canopy where long-wave energy losses cause a strong thermal temperature inversion. The height of the free convection region coincides with the maximum of the plant density distribution.

(4) The model results of Wilson \& Shaw (1977) and Li et al. (1985) simulate the mean within-canopy wind speed profiles within the spatial variability under nearneutral stratification, for above-canopy not too stable states $(L>5 \mathrm{~m})$ and for above-canopy not too unstable states $(L<-60 \mathrm{~m})$. This means that these models can excellently be used in these cases when spatial mean values are required. In all other cases the model results can be used only with much precaution depending on the user's aim.

\section{Acknowledgements}

The authors' gratefully thank the Institute for Land and Water Management (ICW) for making awailable of the facilities of the pilotfarm Sinderhoeve. J. H. van Boxel was supported financially by the Working Group on Meteorology and Physical Oceanography (MFO) from the Netherlands Organization for Advancement of Pure Physics (ZWO). 


\section{References}

Asselt, C. J. van, A. F. G. Jacobs, J. H. Van Boxel, \& A. E. Jansen, 1991. A rigid fast response thermometer for atmospheric research. Measurement Scientific Technology 2: 26-31.

Cionco, R. M., 1972. A wind profile index for canopy flow. Boundary-Layer Meteorology 3: 255-263.

Driedonks, A. G. M.:, 1982. Models and observations of the atmospheric boundary layer. BoundaryLayer Meteorology 23: 283-306.

Graser, E. A., S. B. Verma \& N. J. Rosenberg, 1987. Within-canopy temperature patterns of sorghum at two row spacings. Agriculture and Forest Meteorology 41: 187-205.

Garratt, J. R. \& M. Segal, 1988. On the contribution to dew formation. Boundary-Layer Meteorology 45: 209-236.

Gao, W., R. H. Shaw \& U. K. T. Paw, 1989. Observation of organized structure in turbulent flow within and above a forest canopy. Boundary-Layer Meteorology 47: 349-377.

Hosker, R. P. Jr., C. P. Jr. Nappo \& S. R. Hanna, 1974. Diurnal variation of the structure in a pine plantation. Agriculture and Forest Meteorology 13: 259-265.

Jacobs, A. F. G. \& J. H. van Boxel, 1988a. Changes of the displacement height and roughness length of maize during a growing season. Agriculture and Forest Meteorology 42: 53-62.

Jacobs, A. F. G. \& J. H. van Boxel, 1988b. Computational parameter estimation for a maize crop. Boundary-Layer Meteorology 42: 265-279.

Jacobs, A. F. G., W. A. J. van Pul \& A. van Dijken, 1991, Similarity dew profiles within a corn canopy. Journal of Applied Meteorology 29: 1300-1306.

Li, Z. J., D. R. Miller \& J. D. Lin, 1985. A first-order closure scheme to describe momentum transport in plant canopies. Boundary-Layer Meteorology 33: 77-84.

Meyers, T. \& U, K. T. Paw, 1986. Testing of a higher-order closure model for modeling air flow within and above plant canopies. Boundary-Layer Meteorology 37: 297-311.

Mulhearn, P. J. \& J. J. Finnigan, 1978. Turbulent flow over a very rough, random surface. BoundaryLayer Meteorology 15: 109-132.

Raupach, M. R., 1988. Canopy transport processes. In: W. L. Steffen \& O. T. Denmead, (Eds), Flow and Transport in het Natural Environment, p.95-127. Springer Verlag, Heidelberg/New York.

Shaw, R. H., G. den Hartog, K. M. King, \& G. W. Thurtell, 1974. Measurements of mean wind flow and three dimensional turbulence intensity within a mature corn canopy. Agriculture Meteorology 13: 419-425.

Shaw, R. H., R. H. Silversides \& G. W. Thurtell, 1974. Some observations of turbulence and turbulent transport within and above plant canopies. Boundary-Layer Meteorology 5: 429-449.

Shaw, R. H., 1977. Secondary wind speed maximum inside plant canopies. Journal of Applied Meteorology 5: 429-449.

Shaw, R. H., G. Den Hartog \& H. H. Neumann, 1988. Influence of foliar density on thermal stability on profiles of reynold stress and turbulent intensity in a decideous forest. Boundary-Layer Meteorology 45: 391-409.

Stigter, C., J. Goudriaan, F. A. Bottemanne, J. Birnie, J. G. Lengkeek \& L. Sibma, 1977. Experimental evaluation of a crop climate simulation model for Indian corn (Zea mays L.). Agriculture Meteorology 18: $163-186$.

Tennekes, H. \& J. L. Lumley, 1972. A first course in turbulence. The MIT Press, Cambridge, 300pp.

Tennekes, H., 1982. Similarity relations, scaling laws and Spectral Dynamics. In: F. T. M. Nieuwstadt \& H. van Dop (Eds), Atmospheric Turbulence and Air Pollution Modeling, p. 37-68.

Van Pul, W. A. J. \& J. H. van Boxel, 1989. Comments on: A first-order closure scheme to describe momentum transport in plant canopies. By Z. J. Li, D. R. Miller \& J. D. Lin, Boundary-Layer Meteorology 51: 313-315.

Wilson, N. R. \& R. H. Shaw, 1977. A higher-order closure model for canopy flow. Journal of Applied meteorology 16: 1197-1205.

Wilson, J. D., D. P. Ward, G. W. Thurtell \& G. E. Kidd, 1982. Statistics of atmospheric turbulence within and above a corn canopy. Boundary-Layer Meteorology 24: 495-519. 